NBER WORKING PAPER SERIES

\title{
FOREIGN DIRECT INVESTMENT, EMPLOYMENT VOLATLITY AND CYCLICAL DUMPING
}

Joshua Aizenman

Working Paper No. 4683

\section{NATIONAL BUREAU OF ECONOMIC RESEARCH 1050 Massachusetts Avenue \\ Cambridge, MA 02138 \\ March 1994}

The research reported here is part of the NBER's research program in International Trade and Investment Any opinions expressed are those of the author and not those of the National Bureau of Economic Research. 


\title{
FOREIGN DIRECT INVESTMENT, EMPLOYMENT VOLATILITY AND CYCLICAL DUMPING
}

\begin{abstract}
This paper analyzes the impact of foreign direct investment (FDI) on the pattems of cyclical dumping (exporting at a price below marginal cost). We consider a global oconomy where manufacturing is monopolistic-competitive, and productivity is subject to country-specific shocks. Labor is risk averse and immobile across countries, and entrepreneurs are risk neutral. Labor employment and income is govemed by implicit contracts, which offer stable real income and volatile employment. Capacity investment is irreversible, and is done prior to the resolution of uncertainty. If investment in manufacturing capacity is characterized by retums to scale, higher volatility of productivity shocks is shown to induce producers to diversify intemationally by means of FDI. The resultant integrated equilibrium is characterized by greater volatility of employment as the multinational effectively reallocates employment from a low-realizedproductivity to a high-realized-productivity country. We derive a simple condition characterizing cyclical dumping - it occurs when the percentage shortfall of the realized employment exceeds Lerner's ratio of market power (the inverse of the demand elasticity). Cyclical dumping is more frequent in more competitive and more labor-intensive industries. FDI is shown both to improve welfare, and to increase the incidences of cyclical dumping.
\end{abstract}

Joshua Aizenman Economics Department Dartmouth College Hanover, NH 03755 and NBER 


\section{Introduction and Summary}

The proliferation of foreign direct investment (FDI) in recent years has raised both hopes and concerns. The upbeat view refers to FDI as another form of welfare improving international trade. The more pessimistic view blames FDI for the disappearance of jobs and the decline in real wages of unskilled labor in the United States. Recent studies disputed the last notion, but left open the issue of the implications of FDI on labor employment patterns. 1 The purpose of this paper is to focus on this issue, analyzing the implications of FDI on employment volatility and cyclical dumping in an integrated global economy, subject to country-specific shocks. We consider an economy where the manufacturing sector is characterized by monopolistic competition. Capacity investment is irreversible, and the short-run manufacturing employment is characterized by the absence of labor mobility among producers, where the realized employment and labor income is governed by prenegotiated contracts. The production of a given manufacturing variety requires capital investment in a setup cost, and the employment of a variable input (labor) is subject to diminishing marginal productivity. The capital is characterized by returns to scale, so that the setup cost of investing in two plants is less than twice the set up cost of one plant. The labor market is governed by implicit contracts that guarantee a threshold expected utility. Entrepreneurs are risk neutral, determining the manufacturing capacity and hiring labor ex ante, prior to the realization of productivity shocks.

Our model indicates that FDI, in the presence of returns to scale, is a useful vehicle for the global diversification of producers' exposure to productivity shocks. The diminishing marginal productivity of the variable inputs implies that gains from

1 For a review of FDI, see Lizondo (1990). For empirical studies dealing with FDI see, for example, Froot and Stein (1989), Edwards (1990), Klein and Rosengren (1990), Goldberg (1991), Slaughter (1993) and Brainard (1993). 
- 2 -

diversification occur even if entrepreneurs are risk neutral. These gains are in the form of increasing the flexibility of production and enabling producers to reallocate effective employment from the less- to the more-productive location. Hence, as long as the productivity shocks are not fully correlated across countries, a higher volatility will increase the gains from diversification. If returns to scale are significant enough, higher volatility induces a switch from a nondiversified equilibrium to an integrated global economy. A by-product of this switch is that goods are losing their national identification and, instead, are identified by the multinational producing it. Hence, the international diversification changes the organization of markets, inducing an integrated equilibrium where multinationals command an important role.

To gain clarity, our analysis assumes similarity among the supply and demand conditions facing all producers, implying that there are only two types of equilibria: an integrated world where all goods are produced by multinationals, and a nationalistic equilibrium where a given good is produced only in one country. We identify conditions that will induce a regime switch. It is shown that the move to the integrated equilibrium increases the volatility of employment. The employment of labor under implicit contracts delinks the observed marginal cost of labor from the present market conditions, as the marginal cost of labor is preset, prior to the realization of the state of nature. As Ethier (1982) illustrated, this circumstance implies that occasionally cyclical dumping (defined as exporting at a price below the marginal cost) may be observed. ${ }^{2}$ Our analysis applies this logic for monopolistic competitive industries. We derive a simple condition characterizing cyclical dumping - it occurs when the percentage shortfall of the realized employment, relative to the expected employment, exceeds Lerner's ratio of market power

2 His contribution formulated dumping in a competitive industry where adjustment of some rewards to factors of production is sluggish. Implicit contracts in a HeckscherOhlin framework were studied by Matusz (1985). 


\section{- 3 -}

(defined by the inverse of the demand elasticity). Applying this condition we show that the switch to the integrated equilibrium (induced either by opening capital markets, or due to higher volatility of productivity shocks) increases the incidences of cyclical dumping. Yet, in our model this switch improves welfare of all the involved parties (including labor). Hence, there is no simple correspondence between cyclical dumping and welfare. While one may attempt to associate FDI with more frequent incidences of cyclical dumping, this association is fully consistent with the possibility that FDI is welfare enhancing.

Before continuing it is constructive to place this work in context of the existing literature. FDI is a multifaceted phenomenon explained by several complementary forces. Among the explanations for FDI we find the factor proportions differential hypothesis [Markusen (1984), Helpman (1984)], proximity to markets [Krugman (1983)], informational and technology-control factors [Etheir (1986)]. The approach of the present paper is akin to that of Helpman and Krugman (1985), where returns to scale in the presence of monopolistic competition play a key role in explaining market structure. The scope of this current paper differs, however, as it focuses on the role of uncertainty in inducing FDI in the presence of implicit labor contracts. The gains from the diversification of location via FDI resemble the gains from portfolio diversification obtained in the financial literature. However, in our model these gains are attributed to diminishing marginal productivity of the variable input, and are viable even if agents are risk neutral.

Section 2 presents the key behavioral assumptions of the model. Section 3 characterizes the equilibrium. Section 4 analyzes the implications of production diversification on employment volatility and cyclical dumping. Section 5 closes the paper. The Appendix summarizes the derivation of several key equations. 


\section{The Model}

We review the model by describing the preferences, production, the labor market, the consumers, and the investor's problem. We assume a global economy composed of a large number of countries, denoted by $q$. All the countries are symmetric ex ante, prior to the realization of productivity shocks. Each country is populated with $\vec{L}$ risk-averse workers, and with risk-neutral entrepreneurs.

\section{Preferences}

There are two types of goods: a homogeneous product denoted by $Y$, and $d$ varieties of manufacturing goods. The utility derived from consuming $d$ varieties of the differentiated products is denoted by $D_{2} ; D_{2} i$ is the consumption level of variety $i$ in period 2, and $X_{1}$ is the consumption of the homogeneous good at period 1. Each consumer is endowed with one unit of leisure, a fraction of $l_{2}$ which is spent as work time. The utility of workers is given by

(1) $\quad \ln X_{1}+\frac{1}{1+\rho}\left\{\delta \ln D_{2}+(1-\delta)\left(1-l_{2}\right)\right\}$

where $D_{2}$ is the Dixit-Stiglitz (1977) utility function

(2) $D_{2}=\left[\sum_{i=1}^{d}\left(D_{2, i}\right)^{\alpha}\right]^{1 / \alpha}$

for $0<\alpha<1 ; \rho>0$. The subjective rate of time preference is reflected by $\rho$. This specification assumes risk aversion for goods consumption, but risk neutrality with respect to the consumption of leisure.

The utility of entrepreneurs is given by

(3) $\quad Y_{1}+\frac{1}{1+\rho} D_{2}$, 


\section{$-5-$}

where $D$ is defined by (2). The specification of (3) embodies the notion of risk neutrality of the entrepreneur. Agents in all countries have the same utility function. 3

\section{Broduction}

The economy is endowed in period one with $\bar{Y}$ of the homogeneous good, which serves both as the consumption and investment good in that period.4 The production of good $i$ in the second period in country $c$ is given by

(4) $\quad x_{c, i}=\varepsilon_{d}\left[l \quad c, i L_{c, i}\right]^{\gamma} \quad$ for $0<\gamma<1$.

where $\varepsilon_{c}$ measures the productivity in country $c_{,} L_{c_{r} i}$ is the number of workers employed in the production of variety $i$, each supplying $l_{c, i}$ working time. We assume that the productivity shocks are independently distributed across the various countries, drawn from the same distribution. The production of differentiated products requires also a startup cost in the first period. An entrepreneur may invest in one of the two countries, at a

3 A version of this model was applied by Aizenman (1993) to analyze the merits of fixed versus flexible exchange rates in the presence of nominal contracts. It is shown there that the literature of the eighties overstated the case for a flexible exchange rate regime.

4 To focus the analysis we refrain from modeling the first-period production. One can add production without modifying the key results. For example, one can recast the model in a framework where good $Y$ is replaced with the manufacturing goods produced in the first period, and these goods are used both for consumption and investment purposes. In such a model we start period one with a given capacity that leads to a given manufacturing output. Assuming that capital depreciates within one period (alternatively, that maintaining capacity requires periodic investment $K$ ), one can re derive all our results in such an extended model. 


$$
-6 \text { - }
$$

cost of $\mathrm{K}$. The investment is location- and product-specific, allowing the production of differentiated product at the chosen location. Entrepreneurs may diversify their productive capacity by investing in two locations, at a cost of $K(1+\eta)$, for $\eta \leq 1$. The value of $1-\eta$ measures the returns to scale, associated with the presence of fixed costs that may be shared by both locations.

\section{The Labor Market}

Manufacturing employs labor subject to implicit contracts, hiring L workers under a contract that specifies ex ante state-contingent labor income and employment schedule, denoted by $\left[I_{s} ; l_{s}\right]$, respectively (where $s$ is the state of nature). Competition in the labor market implies that the implicit contract is designed to yield an expected utility in manufacturing that matches the reservation utility level.

\section{Consumer's Demand}

Consumption in the second period is characterized by the solution to

(5)

$$
\begin{array}{ll}
\operatorname{Max} & {\left[\sum_{i=1}^{d}\left(D_{2, i}\right)^{\alpha}\right]^{1 / \alpha}} \\
\text { s.t. } & \sum_{i=1}^{d} P_{2, i} D_{2, i}=\mathbb{N}_{2}
\end{array}
$$

where $p_{2, j} ; \mathbb{N}_{2}$ are the second-period prices of good $i$ and the second-period income, respectively. The solution of the consumer's problem is characterized by

$$
\mathrm{D}_{2, \mathrm{i}}=\left(\frac{\overline{\mathrm{P}}_{2}}{\mathrm{P}_{2, \mathrm{i}}}\right)^{\sigma} \frac{\mathrm{IN}_{2}}{\overline{\mathrm{P}}_{2}}, \text { for } \sigma=1 /(1-\alpha) \text { and } \overline{\mathrm{P}}_{2}=\left[\sum_{\mathrm{i}=1}^{\mathrm{d}}\left(\mathrm{P}_{2, \mathrm{i}}\right)^{-\alpha \sigma}\right]^{-1 /(\alpha \sigma)} \text {. }
$$

The overall CPI is $\overrightarrow{\mathrm{P}}_{2}$. Applying (5) and (6) it follows that 
(7) $\quad \mathrm{D}_{2}=\frac{\mathrm{IN}}{\overline{\mathrm{P}}_{2}}$

The Uncertainty and the Investor's Problem

The uncertainty pertains to the future productivity of labor in the differentiated goods sector. Investment is implemented at period one, prior to the resolution of the uncertainty regarding the productivity in period two. The entrepreneur's utility function (3) is additive. Equations (3) and (7) imply that investment $I$ in period one, generating real profits $\pi_{2}$ in the second period, will be undertaken if $E\left[\pi_{2}\right]-I(1+\rho) \geq 0$. It can be shown that if the supply of $Y$ is large the real interest rate is determined by entrepreneur's preferences $(=1+\rho)$. In such a case, the actual investment is determined by the demand for investment at that real interest rate. Henceforth we assume that this condition is met: the supply of $Y$ is large enough to support the investment demanded at real interest rate $p$. There is free entry, and hence rents are dissipated. A strategy of capacity diversification "buys" the option of channeling production to the more-productive location. More formally, let us denote the real gross profits (revenue minus the wage bill) of a diversified and a specialized producer by $\pi^{\mathrm{d}}$ and $\pi^{\text {nd }}$, respectively. A nondiversified equilibrium, where each producer specializes in one location, can be characterized by
a. $E\left[\pi^{n d}\right]=K(1+\rho)$
b. $E\left[\pi^{\mathrm{d}}\right]<\mathrm{K}(1+\rho)(1+\eta)$

where $E$ stands for the expectation operator, referring to the first-period expected level of second-period profits. 5 Similarly, the diversified equilibrium is characterized by

5 Equation (8a) is generated by the free entry, implying the break-even condition. Condition (8b) implies that the marginal producer does not have an incentive to diversify internationally. The value of $E\left[\pi^{\mathrm{d}}\right]$ is obtained by calculating the profits that will accrue to a marginal producer who will switch to a multinational strategy, assuming that all other producers behave as nondiversified. 

a. $\quad E\left[\pi^{d}\right]=K(1+p)(1+\eta)$
b. $\quad E\left[\pi^{n d}\right]<K(1+\rho)$

A diversified producer operates as a multinational firm, having the capacity to produce his variety in both countries. 6

\section{The Equilibrium}

We will study the equilibrium in several stages. First, we characterize the equilibrium in the absence of FDI, as is the case where (8) holds and producers do not have the incentive to diversify, or if capital is immobile. Next, derive the condition inducing the regime switch from nondiversified to the integrated equilibrium. We then discuss the equilibrium when all producers diversify, as will be the case when (9) is satisfied and capital is mobile.

\section{A Nondiversified Equilibrium}

In the absence of FDI each country produces and exports $m$ varieties of manufacturing goods, importing $\mathrm{m}(\mathrm{q}-1)$ foreign varieties. The nondiversified equilibrium can be characterized by the following conditions:

6 It is noteworthy that entrepreneurs may also increase their production capacity by investing at home in two plants, at a capital cost of $\mathrm{K}(1+\eta)$. In the absence of transportation costs, and in the absence of uncertainty, producers will be indifferent between choosing to produce in two plants operating at home, or one operating at home and one abroad. A small uncertainty (as well as small transportation costs) will suffice to induce producers who operate with two plants to prefer international diversification, benefiting from both the extra capacity and the diversification of country-specific shocks. 
Goods and Labor Market Equilibrium

Equality of the supply and the demand for product $r$ produced by country $c$ implies:

$$
\varepsilon_{c}\left(l_{r, c} L_{r, c}\right)^{\gamma}=\left(\frac{\bar{P}}{P_{r, c}}\right)^{\sigma} \frac{\sum_{j=1}^{q} I N_{j}}{\bar{P}}
$$

where $I N_{j}$ is the income in country $j,(1 \leq j \leq q)$. For notation simplicity we suppress the index indicating the state of nature and the period index, but it is important to keep in mind that, with the exception of the number of workers $\left(L_{r, c}\right)$, all the other variables in (10) are state dependent.

We turn now to study the equilibrium in a representative country. The number of workers, the employment level of each worker, and the real income in terms of the CPI $\left(L ; l_{S} ; I_{S}\right.$ respectively) are determined according to the implicit contract, under which the producer maximizes expected profits subject to the restriction that the worker's expected utility equals the prevailing reservation level:

$$
\underset{L ; l_{s} ; I_{s}}{\operatorname{MAX}} \sum_{s=1}^{z}\left[\frac{P_{s} E_{s}\left[l_{s} L\right]^{\gamma}}{\bar{P}}-I_{s} L\right] \phi_{s}-\lambda\left(\sum_{s=1}^{z}\left[\delta \ln \left(I_{s}\right\}+(1-\delta)\left(1-l_{s}\right)\right] \phi_{s}-\Omega_{0}\right)
$$

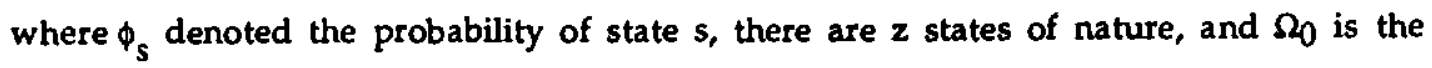
prevailing reservation expected utility level. In solving the above problem the producer recognizes that he faces a demand whose elasticity is $\sigma$, as follows from (10). A more compact way of summarizing the producer's problem is

$$
\operatorname{MAX}_{i l_{s} ; I_{s}} E\left(\frac{\mathrm{P}_{s} E_{s}\left[l_{s} \mathrm{~L}\right]^{\gamma}}{\bar{P}}-I_{s} \mathrm{~L}\right)-\lambda\left(E\left[\delta \ln \left(I_{s}\right\}+(1-\delta)\left(1-l_{s}\right)\right]-\Omega_{0}\right)
$$

where $\mathrm{E}$ is the expectation operator. The corresponding first-order conditions are 
$\left(11^{\prime}\right)$
a. $\quad \alpha \gamma E\left\{\frac{P_{S}}{\bar{P}} x_{s}\right\}=E\left\{I_{s} L\right\}$
b. $\quad \alpha \gamma \frac{\mathrm{Ps}_{\mathrm{s}}}{\overline{\mathrm{P}}} \mathrm{x}_{\mathrm{s}}=\lambda(1-\delta) l_{s}$
c. $\quad I_{S} L=\lambda \delta$

Applying the first-order conditions and equation (10) yields (see the Appendix for an overview of the derivation):
a. $\quad I_{s}=\alpha \gamma E\left[\frac{P_{s} \varepsilon\left[l_{s} L\right]^{\gamma}}{\bar{P}}\right] / L$
b. $\quad E[s]=\frac{\delta}{1-\delta}$

c. $\quad l_{s}=\left[\left\{q \mathrm{mE}\left[\left(\varepsilon_{s}\right)^{\tau}\right]\right\}^{(1-\alpha) / \alpha} \frac{\delta \alpha \gamma}{(1-\delta) 1}\right]^{1 /(1-\gamma)} \frac{\left[\varepsilon_{s}\right]^{\tau}}{L}$ where $\tau=\frac{\alpha}{1-\alpha \gamma}$.

Condition (12a) is in line with the prediction of the implicit contracts literature [see Azariadis (1975)]. Risk-neutral producers would offer a contract that provides complete income insurance, setting the real income of a worker in such a way that labor gets a fixed share $(\alpha \gamma)$ of the expected real revenue. Hence, the equilibrium labor income is state independent:

$$
\text { (12a') } I=I_{s} \text {. }
$$

Condition (12b) implies that the expected employment is determined by the importance of goods consumption relative to leisure, and (12c) determines the actual employment in state s. The labor market equilibrium implies that the total employment equals the labor force, or that

$$
\text { (13) } \mathrm{mL}_{\mathbf{T}}=\overline{\mathrm{L}}
$$

Free entry implies that rents are dissipated. Applying (8a) and (12a) we infer that 
(14) $\mathrm{K}(1+\mathrm{p})=(1-\alpha \gamma) \mathrm{E}\left[\frac{\mathrm{P}_{s} \varepsilon_{s}\left[l_{\mathrm{s}} \mathrm{L}\right]^{\gamma}}{\overline{\mathrm{P}}}\right]$

Combining (10) and (12)-(14) we infer that the number of varieties produced in the economy, and the worker income are (see the Appendix for derivation):
a. $\quad \mathrm{m}=\left[\left(\mathrm{E}\left[(\varepsilon)^{\tau}\right]\right\}^{1 / \tau} q^{(1-\alpha) / \alpha}\left[\overline{\mathrm{L}} \frac{\delta}{1-\delta}\right]^{\gamma} \frac{1-\alpha \gamma}{(1+p) \mathrm{K}}\right]^{\frac{\alpha}{\alpha(1+\gamma)-1}} \quad$ where $\tau=\frac{\alpha}{1-\alpha \gamma}$

b. $\quad I=\frac{\alpha \gamma}{1-\alpha \gamma} \frac{[\mathrm{m}(1+p) \mathrm{K}]}{\overline{\mathrm{L}}}$

We will henceforth assume that the various heterogeneous goods are close substitutes, and that the labor share is large enough that $\alpha(1+\gamma)>1$. This assumption is needed in order to insure that a higher setup cost $\mathrm{K}$ will reduce the number of varieties offered and plays a similar role to the Marshall-Lerner condition in trade theory. ${ }^{7}$

The nondiversified equilibrium is stable if condition (8) is met (or if FDI is prohibited). This will occur if a marginal producer cannot benefit by diversifying internationally, investing in capacity in both countries and employing labor in each country subject to a contract that offers the prevailing reservation utility. In the Appendix we show that the nondiversified regime is stable if

7 It can be shown that the elasticity of expected real profits with respect to the number of varieties is $[1-\alpha(1+\gamma)] / \alpha$. If the demand for the various varieties is relatively inelastic, more varieties will reduce the labor employed in the production of a representative variety, raising thereby profits. This implies that profits will go up with the number of varieties, and that a higher setup cost will imply more producers. The assumption that the varieties are close substitutes rules out this outcome. 


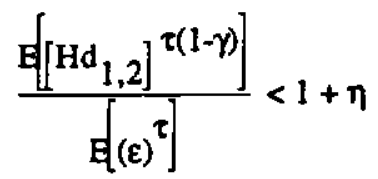

where $\mathrm{Hd}_{1,2}=\left(\varepsilon_{1}\right)^{1 /(1-\gamma)}+\left(\varepsilon_{2}\right)^{1 /(1-\gamma)}, \varepsilon_{1}, \varepsilon_{2}$ being two independent realizations of the productivity shock.

Further insight can be obtained by contrasting two extreme mean invariant configurations of a two-state productivity distribution. First, in the absence of uncertainly, if $\varepsilon=1,(16)$ reduces to $2^{(1-\gamma) \alpha /[1-\alpha \gamma]}<1+\eta$. Hence, if the return to scale is large enough ( $\eta$ small enough), producers will diversify internationally even in the absence of uncertainty. ${ }^{8}$ Alternatively, consider the case in which productivity is given by $\varepsilon=2$ or 0 , each occurring with a probability of one-half (this is the configuration that maximizes the variance, while holding the mean of productivity equal to 1). In these circumstances (16) does not hold (it reduces to $2>1+\eta$ ); hence all producers diversify and an integrated equilibrium is observed. This example illustrates the principle that, if productivity shocks are not perfectly correlated, producers diversify if the volatility is large enough to compensate for the extra capacity cost.

8 This will enable the producer to overcome the diminishing marginal productivity that operates at the level of each plant. In this case, in the absence of transportation costs producers are indifferent between choosing to produce in two plants operating at home, or one operating at home and one abroad. A small uncertainty (as well as small transportation costs) will suffice, however, to induce the international diversification. Inspection of equation (16) reveals that the tendency to diversify internationally depends positively on the international returns to scale (measured by $1-\eta$ ) and the substitutability among the various varieties (measured by $\alpha$ ). 
If condition (16) is violated, we observe an integrated equilibrium where all producers diversify. We turn now to evaluate the integrated equilibrium, assuming that the conditions for diversification hold.

\section{Diversified Equilibrium}

The symmetric nature of our framework implies that if the condition for international diversification applies, all producers would choose to operate as multinationals, producing in two countries. If each country produces $\mathbf{n}$ goods, the total number of goods is $0.5 \mathrm{nq}$. The goods market equilibrium for a representative good $r$, produced in countries $\mathrm{c} 1$ and $\mathrm{c} 2$, equates the global supply-and-demand conditions

$$
\varepsilon_{\mathrm{cl} 1}\left(l_{\mathrm{r}, \mathrm{cl}} \mathrm{L}_{\mathrm{r}, \mathrm{c} 1}\right)^{\gamma}+\varepsilon_{\mathrm{c} 2}\left(l_{r, \mathrm{c} 2} \mathrm{~L}_{\mathrm{r}, \mathrm{c} 2}\right)^{\gamma}=\left(\frac{\overline{\mathrm{P}}}{\mathrm{P}_{\mathrm{r}}}\right)^{\sigma} \frac{\sum_{\mathrm{j=1}}^{q} \mathbb{N}_{\mathrm{j}}}{\overline{\mathrm{P}}}
$$

The labor contract offered by the multinational is the outcome of

$$
\left[\begin{array}{c}
E\left\{\frac{P_{r}}{\overline{\bar{P}}}\left\{\varepsilon_{c 1}\left[l_{c 1} L_{c 1}\right]^{\gamma}+\varepsilon_{c 2}\left(l_{c 2} L_{c 2}\right)^{\gamma}\right]-I_{c 1} L_{c 1}-1 \text { c2 }{ }_{c 2}\right\} \\
-\lambda_{c 1}\left(E\left[\delta \ln \left(I_{c 1}\right\}+(1-\delta)\left(1-l_{c 1}\right)\right]-\Omega_{c 1}\right) \\
-\lambda_{c 2}\left(E\left[\delta \ln \left(I_{c 2}\right\}+(1-\delta)\left(1-l_{c 2}\right)\right]-\Omega_{c 2}\right)
\end{array}\right]
$$

For notation simplicity we suppress the state index, but one should keep in mind that with the exception of $\mathrm{L}_{\mathrm{cl}} ; \mathrm{L}_{\mathrm{c} 2}$ which are ex ante determined, all the other variables are state contingent. Note that the multinational produces in both countries and deals with two labor contracts, corresponding to the labor markets in the two countries. Our symmetric specification implies that in the resultant equilibrium the same labor contract is applied in both countries. Applying the resulting first-order conditions yields (see the Appendix for further details): 


$$
\begin{aligned}
& \text { a. } \quad 1_{s}=\alpha \gamma \mathrm{E}\left[\frac{\mathrm{Ps}_{s} \varepsilon_{s}\left[l_{s} L\right]^{\gamma}}{\widetilde{\mathbf{P}}}\right] \\
& \text { (19) b. } \quad E[s]=\frac{\delta}{1-\delta} \\
& \text { c. } \left.l_{s}=\left\{\frac{\mathrm{n} q}{2} \mathrm{E}\left[\mathrm{Hd}_{1,2}\right]^{\tau(1-\gamma)}\right]\right\}^{(1-\alpha) /[\alpha(1-\gamma)]}\left(\frac{\alpha \gamma \delta}{(1-\delta) 1}\right\}^{1 /(1-\gamma)} \frac{\left[\varepsilon_{\mathrm{c} 1}\right]^{1 /(1-\gamma)}}{\mathrm{L}\left\{\mathrm{Hd}_{1,2}\right\}^{(1-\alpha) /(1-\alpha \gamma)}} \\
& \text { where } \quad \operatorname{Hd}_{1,2}=\left(\varepsilon_{\mathrm{c} 1}\right)^{1 /(1-\gamma)}+\left(\varepsilon_{\mathrm{c} 2}\right)^{1 /(1-\gamma)} \text {. }
\end{aligned}
$$

The labor market equilibrium implies that total employment equals the labor force, or that

$$
\text { (20) } \mathrm{nL}_{\mathrm{r}}=\overline{\mathrm{L}}
$$

Free entry implies that rents are dissipated, or that (which follows from (9a) and (18a))

(21) $K(1+\rho)(1+\eta)=2(1-\alpha \gamma) E\left[\frac{P_{s} \varepsilon\left[l_{s} L\right]^{\gamma}}{\overline{\mathbf{P}}}\right]$

Combining (19)-(21) we infer that the number of varieties produced by each country, and the real labor income are (see the Appendix for further details):

(22)

$$
\begin{aligned}
& \text { a. } \left.\quad \mathrm{n}=\left[\left\{\left[\frac{\left(\varepsilon_{s}\right)^{1 /(1-\gamma)}}{\left[\mathrm{Hd}_{1,2}\right]^{(1-\alpha) /(1-\alpha \gamma)}}\right]\right\}^{1-\gamma}\left\langle\frac{q}{2} \mathrm{E}\left[\mathrm{Hd}_{1,2}\right]^{\tau(1-\gamma)}\right]\right\}^{(1-\alpha) / \alpha}\left[\frac{\delta \bar{L}}{1-\delta}\right]^{\gamma} \frac{2(1-\alpha \gamma)}{(1+\rho) \mathrm{K}(1+\eta)}\right]^{\frac{\alpha}{\alpha(1+\gamma)-1}} \\
& \text { b. } \quad 1=\frac{\alpha \gamma}{1-\alpha \gamma} \frac{[0.5 \mathrm{n}(1+\rho) \mathrm{K}(1+\eta)]}{\overline{\mathrm{L}}}
\end{aligned}
$$


$-15-$

\section{Employment Volatility. Production Diversification, and Cyclical Dumping}

In order to characterize the conditions leading to cyclical dumping in the two regimes, we will start with comparison of the volatility of employment. Applying (12c) we find that the elasticity of employment in country $\mathrm{cl}$ with respect to productivity shocks in the nondiversified regime are

$$
\left[\frac{d \log l_{c 1}}{d \log \varepsilon_{c 1}}\right]_{\text {lnd }}=\frac{\alpha}{1-\alpha \gamma} ; \quad\left[\frac{d \log l_{c l}}{d \log \varepsilon}\right]_{\text {lnd }}=0
$$

where $\varepsilon$ is the productivity shock in another country, and index 'nd' stands for the nondiversified regime. Applying (19c) we infer that the corresponding employment elasticities facing a multinational that produces in countries $c 1$ and $c 2$ in the integrated equilibrium are:

$$
\left[\frac{\mathrm{d} \log l_{\mathrm{cl}}}{\mathrm{d} \log \varepsilon_{\mathrm{c} 1}}\right]_{\mathrm{ld}}=\frac{1+\alpha(1-2 \gamma)}{2(1-\gamma)(1-\alpha \gamma)} ; \quad\left[\frac{\mathrm{d} \log l_{\mathrm{cl}}}{\mathrm{d} \log \varepsilon_{\mathrm{c} 2}}\right]_{\mathrm{ld}}=-\frac{1-\alpha}{2(1-\gamma)(1-\alpha \gamma)} ;\left[\frac{\mathrm{d} \log l_{\mathrm{cl}}}{\mathrm{d} \log \varepsilon^{*}}\right]_{\mathrm{ld}}=0 .
$$

where $\varepsilon^{*}$ is the productivity shock in a country where the multinational has not invested, and index $d$ stands for the diversified regime. Comparison of the two regimes reveals that the diversification of production magnifies the responsiveness of employment to domestic productivity, and transmits negatively foreign productivity shocks. 9 Note that:

$$
\text { (25) }\left[\frac{d \log l_{c 1}}{d \log \varepsilon_{c 1}}-\frac{d \log l_{c 1}}{d \log \varepsilon^{*}}\right]_{\operatorname{lod}}=\frac{\alpha}{1-\alpha \gamma} ;\left[\frac{d \log l_{c 1}}{d \log \varepsilon_{c 1}}-\frac{d \log l_{c 1}}{d \log \varepsilon_{c 2}}\right] l d=\frac{1}{1-\gamma}
$$

Hence, employment is more responsive to domestic shocks than to foreign shocks in both regimes, and the move towards the integrated equilibrium increases the differential

9 From (24) and (25) we infer that $\left[\frac{d \log l_{c 1}}{d \log \varepsilon_{c 1}}\right] l_{d}^{-}\left[\frac{d \log l_{c 1}}{d \log \varepsilon_{c 1}}\right]$ lnd $=\frac{1-\alpha}{2(1-\alpha \gamma)(1-\gamma)}>0$. 
- 16-

responsiveness. The greater flexibility of production exhibited by multinationals is reflected by its ability to shift effective employment towards the location exhibiting the more favorable productivity shock, increasing the responsiveness of labor to domestic productivity shocks. The resultant international diversification of production implies, however, that the volatility of employment goes up. This suggest that we should expect more frequent episodes of dumping in the integrated equilibrium. We turn now to evaluate this issue.

\section{International Diversification and Cyclical Dumping}

The organization of labor markets under implicit contracts implies the delinking of the real wage from the current state of nature. In these circumstances we may occasionally observe "cyclical dumping," where producers export at a price below the marginal cost of production. 10 One possible measure of dumping is the degree to which the marginal cost exceeds the price. According to this definition, cyclical dumping occurs if

$$
I \frac{1}{\partial x_{S} / \partial L}>\frac{P_{S}}{\bar{P}_{S}} \text {. }
$$

The left-hand side is the marginal cost - computed as the labor compensation times the reciprocal of the marginal productivity of labor in state s. Applying (4) and the first-order conditions characterizing the implicit contract, it follows that cyclical dumping occurs in states of nature where ${ }^{11}$

10 This follows from the fact that the labor income (on which the marginal cost depends positively) is preset prior to the resolution of uncertainty. In bad times, the MC goes up at a rate that exceeds the rate of price increase, as the labor income is not responsive to productivity, leading to the possibility of dumping.

11 Equation (4) implies that (26) is equivalent to $\frac{L L}{\gamma \pi_{s}}>\frac{P_{S}}{\bar{P}_{S}}$. Applying (11') we infer that $\alpha \gamma \frac{P_{s}}{\bar{P}} x_{s}=\frac{1-\delta}{\delta} / s I_{s} L$. Combining these two conditions we derive (26). 


$$
\frac{1}{\sigma}<\frac{\delta /(1-\delta)-l}{\delta /(1-\delta)}
$$

The LHS is Lerner's measure of the market power enjoyed by the producer (the inverse of the demand elasticity). The RHS measures the percentage decline of employment relative to expected employment, $\delta /(1-\delta)$ [ note that $\delta /(1-\delta)$ corresponds to full employment in the absence of uncertainty]. Hence, cyclical dumping occurs where the producer's market power is smaller than the percentage shortfall of employment. Applying the previous results we infer that cyclical dumping in the nondiversified equilibrium will occur when 12

$$
\alpha>\frac{(\varepsilon)^{\tau}}{\left[(\varepsilon)^{\tau}\right]}
$$

In the diversified regime the corresponding condition is:

(28) $\alpha>\frac{\left(\varepsilon_{1}\right)^{1 /(1-\gamma)}\left[\mathrm{Hd}_{1,2}\right]^{(1-\alpha) /(1-\alpha \gamma)}}{\left.E\left[\varepsilon_{1}\right)^{1 /(1-\gamma)}\left[\mathrm{Hd}_{1,2}\right]^{(1-\alpha) /(1-\alpha \gamma)}\right]}$.

To gain further insight, it is constructive to turn to the simplest stochastic example: two states of nature in each country, with equal probability of occurrence, independently distributed across the $q$ countries. While being a special case, it allows us to highlight the role of uncertainty in determining the employment and cyclical dumping. Each country can experience with probability 0.5 either high or low productivity:

$$
\varepsilon=1+h \text { or } 1-h ; \quad h>0
$$

The functioning of the global economy can be summarized with the help of Figures 1-2. While they focus on a special case, the qualitative results reported in these figures can be

12 Applying (12c) to (26') we obtain a condition with $m$ and I. Replacing these variables with (15a) and (15b), collecting terms, we infer (27). A similar procedure [applying (19c), (22a) and (22b) to (26')] yields (28). 
shown to be general. We choose the return-to-scale parameter $\eta$ such that in the absence of shocks producers are indifferent between operating one versus two plants (i.e., $\left.2^{(1-\gamma) \alpha /[1-\alpha \gamma]}=1+\eta\right)$. The solid curves (denoted by nd) correspond to the nondiversified regime, whereas the dotted curves (denoted by $d$ ) to the integrated equilibrium. Figure 1 reports the pattern of labor income in the two regimes. The figure provides the information needed to compare labor's expected utility in the two regimes. ${ }^{13}$ Figure 2 reports the employment in the good state in both regimes. The employment in the bad state is a mirror image of the good state (reflected on $l=1 / 3$, as the sum of the employment in both states of nature adds up to $2 / 3$ ).

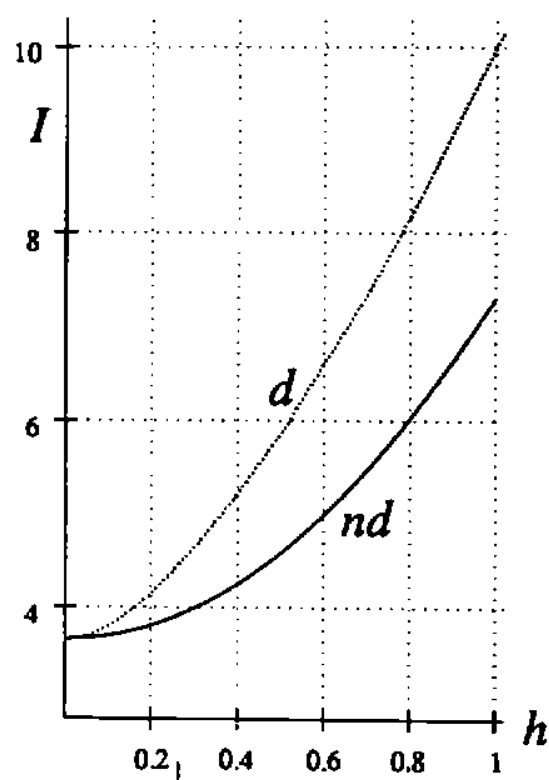

Figure 1: Labor income

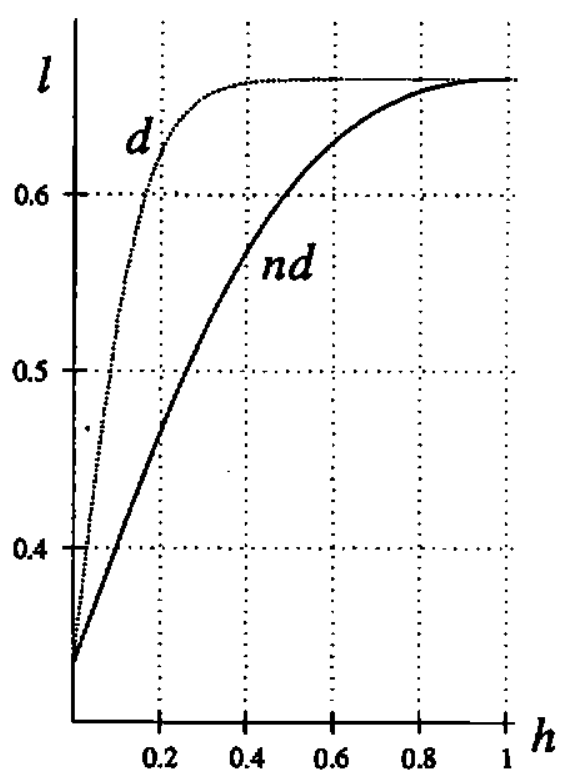

Figure 2: Employment in the good state

The above example assumes $\gamma=0.85, \alpha=0.75, \delta=0.25, K=1.2, \overline{\mathrm{L}}=100, q=14$ and $p=0$

13 Note that the worker's second period expected utility is $E\left(\delta \ln D_{2}+(1-\delta)\left(1-l_{2}\right)\right\}=\delta \ln I+(1-2 \delta)$. Hence, it is fully determined by $I$. 
- 19 -

For the two states of nature example considered, dumping in the nondiversified equilibrium occurs if

$$
\alpha>\frac{2(1-h)^{\tau}}{[1+h]^{\tau}+[1-h]^{\tau}}
$$

and the corresponding conditions in the integrated equilibrium is

a.

$$
\alpha>\frac{\left.4(1-h)^{1 /(1-\gamma)} /(1-h)^{1 /(1-\gamma)}+(1+h)^{1 /(1-\gamma)}\right]^{(1-\alpha) /(1-\alpha \gamma)}}{\left[(1-h)^{1 /(1-\gamma)}+(1+h)^{1 /(1-\gamma)}\right]^{(1-\alpha) /(1-\alpha \gamma)}+\left[(1-h)^{\tau}+(1+h)^{\tau}\right] 2^{-(1-\alpha) /(1-\alpha \gamma)}}
$$

b.

$$
\alpha>\frac{4(1-h)^{1 /(1-\gamma)}\left[2(1-h)^{1 /(1-\gamma)}\right]^{(1-\alpha) /(1-\alpha \gamma)}}{\left[(1-h)^{1 /(1-\gamma)}+(1+h)^{1 /(1-\gamma)]^{(1-\alpha) /(1-\alpha \gamma)}}+\left[(1-h)^{\tau}+(1+h)^{\tau}\right] 2^{-(1-\alpha) /(1-\alpha \gamma)}\right.}
$$

Recalling that a multinational operates two plants in two countries (say countries 1 and 2), there are two possible configurations associated with dumping by country 1 . Condition (28'a) corresponds to the case where productivity in country 1 is low while the productivity in country 2 is high. Condition $\left(28^{\prime} b\right)$ corresponds to the case where the productivity is low in both countries. Curves nd and $d_{1}$ in Figure $3 a$ plot the configurations of volatility and substitutability ( $h, \alpha(b))$ associated with equality in (27') and (28'a), respectively. Dumping in a given regime occurs for points that are above the corresponding curve. Direct inspection of $\left(27^{\prime}\right)$ and $\left(28^{\circ}\right.$ a) reveals that both curves are downward sloping, starting at point $(0,1)$ and asymptotically approaching point $(1,0)$. The curves are downward sloping because larger market power (smaller $\alpha$ ) implies higher mark-up, reducing the scope for observing prices that fall short of marginal costs. This in turn implies that with greater 
market power the volatility threshold associated with dumping goes up (because dumping would require worse realization of productivity shocks). ${ }^{14}$

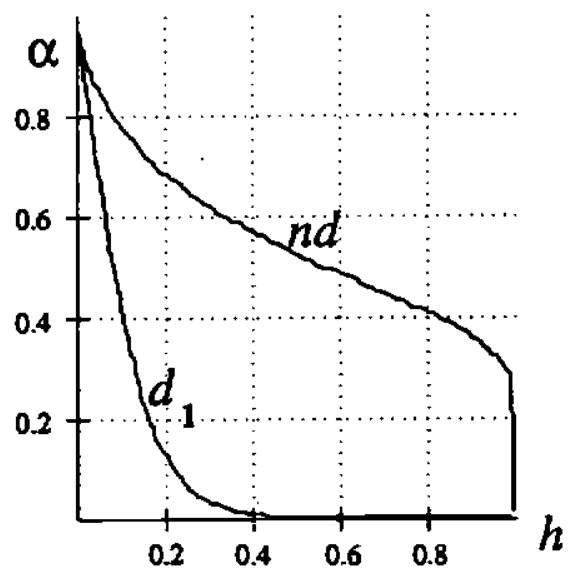

a.

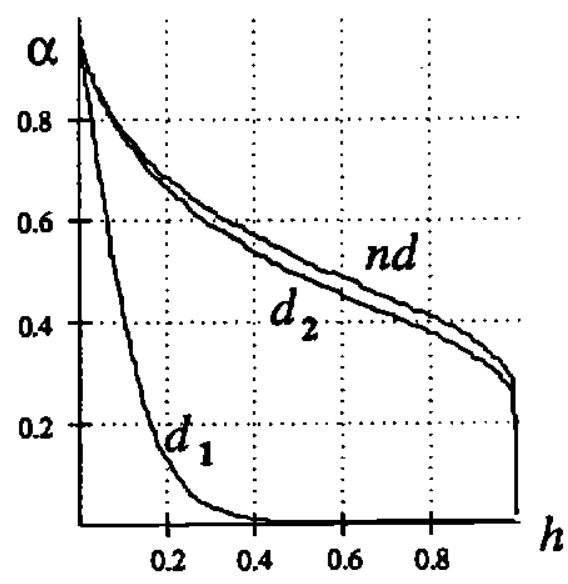

b.

Figure 3: Volatility and Cyclical Dumping

Further inspection of $\left(27^{\prime}\right)$ and $\left(28^{\prime} a\right)$ reveals that curve nd is further to the right of curve $d$. The higher volatility of employment in the integrated equilibrium implies that FDI increases the plausibility that $\left(26^{\prime}\right)$ is satisfied in bad states of nature, where the multinational effectively reallocates marginal employment from the low- to the highproductivity country. Hence, the volatility threshold associated with dumping is lower in the integrated regime. The area locked between curves $d_{1}$ and nd defines the volatility region associated with dumping in the integrated regime, but with no dumping in the

14 Inspection of (27') and (28') also reveals that a lower share of the variable input (lower $\gamma$ ) will shift the curves in Figure 3 to the right. This follows from the observation that lower labor share increases the markup, reducing the scope for dumping, increasing thereby the threshold of volatility associated with dumping. 
nondiversified regime. Figure $3 b$ adds curve $d_{2}$, corresponding to $(28$ ' $b$ ), where the low productivity shock hits both plants used by the multinational. While this case qualitatively resembles the first case (i.e., both curves $d_{1}$ and $d_{2}$ are to the left of nd), dumping is less likely in this circumstance. When low productivity affects both plants, supply goes down, the price is higher, and dumping less likely (relative to the case where only country 1 suffers from low productivity).

It can be shown that for the example considered in Figures 1 and $2(\alpha=0.75, \gamma=0.85$ ), dumping in the bad state of nature will occur for $h>.038$ in the integrated regime, and for $h>0.123$ in the absence of FDI. ${ }^{15}$ For example, suppose that volatility $h$ is 0.1 , and FDI is prohibited. Employment would fluctuate between 0.43 and 0.20 in the good and the bad state, respectively, and we would not observe dumping. Opening the economies to unrestricted FDI will induce an integrated equilibrium where employment volatility increases remarkably (fluctuating between .58 and .08 ). In the resulting equilibrium the country experiencing the bad shock dumps its product. It will be misleading to infer from this, however, that FDI is harmful. The greater flexibility of production achieved by diversification generates efficiency gains, which ultimately are reflected in higher labor income and higher aggregated investment. In our example, the move to the integrated equilibrium raises the labor income by about $3 \%$ (from 3.69 to 3.79 ).

15 This calculation assumes that productivity is low in country 1, and high in country 2 (and thus dumping in the integrated regime is described by curve $d_{1}$ ). 


$$
\text { - } 22 \text { - }
$$

\section{Concluding Remarks}

Our paper illustrated that in a world characterized by labor contracts and trade among similar countries subject to country-specific shocks, FDI increases both the volatility of employment, and the incidences of cyclical dumping. The model illustrates an example where FDI and the induced cyclical dumping are welfare enhancing. In closing the paper it is useful to qualify these results as being model specific and thus not to be taken as general welfare statements. Instead, the paper should serve to caution against making welfare inferences without a more careful specification of the economic structure. The assumption that all countries are identical ex ante leads to more elegant formulation that is easier to interpret, but it may leave out important issues that should be addressed in an attempt to unravel the welfare effects of dumping. For example, if countries differ in the functioning of labor markets, some relying more heavily on implicit contracts, others more heavily on the spot labor market, FDI may have more complex and less clear-cut welfare implications. 


$$
\text { - } 23 \text {. }
$$

\section{Appendix}

The purpose of this Appendix is to provide the detailed derivation of equations 12 , $15,16,19$ and 22.

\section{Equation 12:}

The first-order conditions corresponding to (11) are
(A1)
a. $\quad \alpha \gamma E\left\{\frac{P_{s}}{\bar{P}} x_{s}\right\}=E\left(I_{s} L\right)$
b. $\quad \alpha \gamma \frac{\mathrm{P}_{\mathrm{S}}}{\overline{\mathrm{P}}} \pi_{\mathrm{s}}=\lambda(1-\delta) l_{\mathrm{s}}$
c. $I_{s} L=\lambda \delta$

Equation (A1c) implies that labor income is state independent. Applying this information to (Ala), infer (12a). Dividing condition (AIb) and (AIc) (in order to eliminate $\lambda$ ), applying the expectation operator to the resultant equation, and applying to it condition (A1a), infer (12b). The derivation of (12 c) is more involved. First, applying (10) obtain that the relative price of goods produced by country $\mathrm{cl}$ and $\mathrm{c} 2$ satisfies

(A2)

$$
\frac{\varepsilon_{\mathrm{c} 1}}{\varepsilon_{\mathrm{c} 2}}\left(\frac{l_{\mathrm{c} 1}}{l_{\mathrm{c} 2}}\right)^{\gamma}=\left(\frac{\mathrm{P}_{\mathrm{c} 2}}{\mathrm{P}_{\mathrm{c} 1}}\right)^{\sigma}
$$

Applying (A1b) infer that

$$
\text { (A3) } \frac{\mathrm{p}_{\mathrm{c} 1} \varepsilon_{\mathrm{c} 1}}{\mathrm{P}_{\mathrm{c} 2} \varepsilon_{\mathrm{c} 2}}\left(\frac{l_{\mathrm{c} 1}}{l_{\mathrm{c} 2}}\right)^{\gamma}=\frac{l_{\mathrm{c} 1}}{l_{\mathrm{c} 2}}
$$

Combining the last two equations infer that ${ }^{16}$

(A4) $\frac{l_{\mathrm{c} 1}}{l_{\mathrm{c} 2}}=\left(\frac{\varepsilon_{\mathrm{cl}}}{\varepsilon_{\mathrm{c} 2}}\right)^{\alpha /(1-\alpha \gamma)}$

Equation (10) can be rearranged as

16 Note that the problem facing entrepreneurs producing different varieties is symmetric, implying that all of them employ the same $L$, and face the same $\lambda$. 
(10) $\left(\frac{p_{c}}{\overline{\bar{P}}}\right)^{\alpha \sigma}=\sum_{j=1}^{q}\left[\frac{\varepsilon_{j}\left(l_{j}\right)^{\gamma} p_{j}}{\varepsilon_{c}\left(l_{c}\right)^{\gamma} p_{c}}\right]$

Applying (A3) and (A4) to the RHS of (10'), infer that

$$
\text { (A5) }\left(\frac{p_{c}}{\bar{P}}\right)^{\alpha \sigma}=\frac{1}{\left(\varepsilon_{c}\right)^{\alpha /(1-\alpha \gamma)}} \sum_{j=1}^{q} m\left(\varepsilon_{j}\right)^{\alpha /(1-\alpha \gamma)} \text {. }
$$

Assuming that the number of countries $(q)$ is large, invoke the law of large numbers to (A5), implying that

$$
\text { (A6) } \frac{\sum_{j=1}^{q}\left(\varepsilon_{j}\right)^{\alpha /(1-\alpha \gamma)}}{q} \cong E\left[\varepsilon^{\alpha /(1-\alpha \gamma)]} .\right.
$$

Hence,

$$
\text { (A7) } \left.\left(\frac{p_{c}}{\overline{\mathrm{P}}}\right)^{\alpha \sigma} \cong \frac{\mathrm{m} q}{\left(\varepsilon_{\mathrm{c}}\right)^{\alpha /(1-\alpha \gamma)}} \mathrm{E}(\varepsilon)^{\alpha /(1-\alpha \gamma)}\right]
$$

Applying (Ala) and (A1b) infer that

$$
\text { (A8) }\left[l_{\mathrm{s}} \mathrm{L}\right]^{1-\gamma}=\alpha \gamma \frac{\mathrm{p}_{\mathrm{s}}}{\overline{\mathrm{P}}} \varepsilon_{\mathrm{s}} \frac{\delta}{(1-\delta) I}
$$

Applying (A7) to (A8) infer (12c).

\section{Equation (15):}

Equations (12a), (12c), (13), (14), and (A6) form a simultaneous equations system that allows us to solve for $\left[\frac{p_{c}}{\bar{P}}, m, I, L_{r}, l\right]$ as a function of structural variables (like $q, K$, and the productivity distribution). Equation (15) is the outcome of solving this system.

\section{Equation (16)}

Consider the problem facing a marginal entrepreneur located in country $c 1$ who wishes to diversify, becoming a multinational that produces in country $c 1$ and $c 2$, while all 
$-25-$

other producers operate from one location. Denote by $p_{d}, l_{d}, L_{d}$ the price charged, the working time, and the number of workers employed by the diversified producer. Applying equation (6) it follows that the price is determined by the following marketclearing condition:

(A9) $\varepsilon_{\mathrm{cl}}\left(l_{\mathrm{d}, \mathrm{cl}} \mathrm{L}_{\mathrm{d}, \mathrm{cl}}\right)^{\gamma}+\varepsilon_{\mathrm{c} 2}\left(l_{\mathrm{d}, \mathrm{c2}} \mathrm{L}_{\mathrm{d}, \mathrm{c} 2}\right)^{\gamma}=\left(\frac{\overline{\mathrm{P}}}{\mathrm{P}_{\mathrm{d}}}\right)^{\sigma} \frac{\sum_{j=1}^{q} \mathrm{IN}_{\mathrm{j}}}{\overline{\mathrm{P}}}$ Compare the price of the good produced by the diversified entrepreneur, to the price of variety $\mathrm{r}$ produced in country $\mathrm{c1}$ by a nondiversified producer. Applying (10) and (A9) we infer that:

$$
\text { (A10) } \frac{\varepsilon_{\mathrm{cl}}\left(l_{\mathrm{d}, \mathrm{cl}} \mathrm{L}_{\mathrm{d}, \mathrm{cl}}\right)^{\gamma}+\varepsilon_{\mathrm{c} 2}\left(l_{\mathrm{d}, \mathrm{c} 2} \mathrm{~L}_{\mathrm{d}, \mathrm{c} 2}\right)^{\gamma}}{\varepsilon_{\mathrm{cl}}\left(l_{\mathrm{r}, \mathrm{cl}} \mathrm{L}_{\mathrm{r}, \mathrm{cl}}\right)^{\gamma}}=\left(\frac{\mathrm{p}_{\mathrm{r}}}{\mathrm{P}_{\mathrm{d}}}\right)^{\sigma}
$$

The nondiversified regime is stable if in the resultant equilibrium the expected profits for a multinational are below the cost of capital:

(A11) $(1-\alpha \gamma) E\left\{\frac{p_{d}}{\overline{\bar{P}}}\left[\varepsilon_{c 1}\left[l_{d, c 1} L_{d}\right]^{\gamma}+\varepsilon_{c 2}\left(l_{d, c 2} L_{d}\right)^{\gamma}\right]\right\}<K(1+\rho)(1+\eta)$.

Such an entrepreneur offers two implicit contracts to the labor employed in $c 1$ and $c 2$, each guaranteeing expected utility that equals the market reservation utility level. The ex ante symmetry of the two countries implies that these contracts are identical. Direct derivation of these contracts reveals that the first-order conditions in (A1) continue to apply for each country. Applying this information to the first order conditions in (A1), and comparing 
the work time in the multinational's plant in country $\mathrm{cl}$ with the work time in a nondiversified producer in country $\mathrm{cl}$ infer that 17

(A12) $\quad \frac{l_{\mathrm{d}, \mathrm{cl}} \mathrm{L}_{\mathrm{d}}}{l_{\mathrm{r}} \mathrm{L}_{\mathrm{r}}}=\left(\frac{\mathrm{p}_{\mathrm{d}}}{\mathrm{p}_{\mathrm{r}}}\right)^{1 /(1-\gamma)}$.

Applying (A10) and (A12) to (A9) infer that

$$
\left\{\frac{\left(\varepsilon_{\mathrm{cl}}\right)^{1 /(1-\gamma)}+\left(\varepsilon_{\mathrm{c} 2}\right)^{1 /(1-\gamma)}}{\left(\varepsilon_{\mathrm{c} l}\right)^{1 /(1-\gamma)}}\right\}^{(1-\alpha)(1-\gamma) /(1-\alpha \gamma)}=\frac{\mathrm{p}_{\mathrm{r}}}{\mathrm{p}_{\mathrm{d}}}
$$

Note that in the nondiversified regime

$$
\text { (A14) } \quad(1-\alpha \gamma) E\left\{\frac{\mathrm{p}_{d}}{\overline{\mathrm{p}}}\left[\varepsilon_{\mathrm{cl}}\left[l_{\mathrm{r}} \mathrm{L}_{\mathrm{r}}\right]^{\gamma}\right]\right\}=\mathrm{K}(1+\rho)
$$

Applying this condition to (A11) infer that the nondiversified regime is stable if

$$
\text { (A15) }(1-\alpha \gamma) E\left\{\frac{\mathrm{P}_{\mathrm{r}}}{\overline{\overline{\mathrm{P}}}} \frac{\mathrm{P}_{\mathrm{d}}}{\mathrm{P}_{\mathrm{r}}}\left[\varepsilon_{\mathrm{c} 1}\left[l_{\mathrm{d}, \mathrm{cl}} \mathrm{L}_{\mathrm{d}}\right]^{\gamma}+\varepsilon_{\mathrm{c} 2}\left(l_{\mathrm{d}, \mathrm{c} 2} \mathrm{~L}_{\mathrm{d}}\right)^{\gamma}\right]\right\}<(1-\alpha \gamma) \mathrm{E}\left\{\frac{\mathrm{p}_{\mathrm{d}}}{\overline{\mathrm{P}}}\left[\varepsilon_{\mathrm{c} 1}\left[l_{\mathrm{r}} \mathrm{L}_{\mathrm{r}}\right]^{\gamma}\right]\right\}(1+\eta)
$$

Applying (A7), (A12), (A13) to (A15), collecting terms and using (12c) obtain (16).

\section{Equation (19):}

The first-order conditions that correspond to the implicit contract offered to labor in c1 and $c 2$ are identical to (A1), but each country has its own corresponding Lagrange multiplier. Applying the logic discussed at the beginning of the Appendix (19a) can be

17 This is obtained by taking the ratios of the two first order conditions (A1b) that apply to both producers. 


\section{-27 -}

inferred. From the first-order conditions it follows that the working time in the multinational's two plants are given by

$$
\text { (A16) } \frac{l_{\mathrm{c} 1}}{l_{\mathrm{c} 2}}=\left(\frac{E_{\mathrm{c} 1}}{E_{\mathrm{c} 2}}\right)^{1 /(1-\gamma)}
$$

In the integrated equilibrium each good $i$ is produced in two countries. Denote by cil and $\mathrm{ci} 2$ the two countries where product $\mathrm{i}$ is produced, $1 \leq \mathrm{i} \leq 0.5 q \mathrm{n}$. Suppose that $\operatorname{good} \mathrm{r}$ is produced in country 1 and 2. Equation (10) can be rearranged as

$$
\text { (A17) }\left(\frac{p_{r}}{\overline{\mathrm{P}}}\right)^{\alpha \sigma}=\sum_{j=1}^{0.5 n q} \frac{\left[\varepsilon_{\mathrm{ci1}}\left(l_{\mathrm{ci} 1}\right)^{\gamma}+\varepsilon_{\mathrm{ci} 2}\left(l_{\mathrm{c} 2}\right)\right)^{\gamma} \mathrm{p}_{\mathrm{i}}}{\left[\varepsilon_{1}\left(l_{1}\right)^{\gamma}+\varepsilon_{2}\left(b_{2}\right)^{\gamma} \mathrm{p}_{\mathrm{r}}\right.}
$$

Applying (A1b) and (Alc) infer that for good i

$$
\text { (A18) I L } \frac{\delta}{1-\delta}\left[l_{\text {cil }}+l_{\text {ci2 }]}\right]=\alpha \gamma \frac{P_{i}}{\bar{P}}\left[E_{\text {ci1 }}\left(l_{\text {cil }} L\right)^{\gamma}+E_{\text {ci2 }}\left(l_{\text {ci2 }} L\right)^{\gamma}\right]
$$

Applying (A16) to (A18) infer that

$$
\text { (A19) } \quad I \frac{\delta}{I-\delta}=\alpha \gamma \frac{P_{i}}{\bar{P}}\left(l_{\text {cil }} L\right)^{\gamma-1} \varepsilon_{\text {cil }}
$$

Applying (A19) for good $r$, and dividing the resultant equation by (A19) infer that

$$
\frac{p_{i}}{p_{r}}=\left(\frac{l_{\text {cil }}}{l_{\mathrm{r} l}}\right)^{l-\gamma} \frac{\varepsilon_{\mathrm{r}}}{\varepsilon_{\text {cil }}}
$$

Applying (A16) and (A20) to (A17) infer that

$$
\left(\frac{\mathrm{p}_{\mathrm{r}}}{\overline{\mathrm{P}}}\right)^{\alpha \sigma}=\sum_{j=1}^{0.5 n g} \frac{\left[\mathrm{Hd}_{\mathrm{ci} 1, \mathrm{ci} 2}\right]^{\alpha(1-\gamma) /(1-\alpha \gamma)}}{\left[\mathrm{Hd}_{1,2}\right]^{\alpha(1-\gamma) /(1-\alpha \gamma)}} \quad \text { where } \mathrm{Hd}_{\mathrm{ci} 1, \mathrm{ci} 2}=\left(\varepsilon_{\mathrm{ci} 1}\right)^{1 /(1-\gamma)}+\left(\varepsilon_{\mathrm{ci} 2}\right)^{1 /(1-\gamma)}
$$

Assuming that the number of countries $(q)$ is large, the law of large numbers can be invoked, implying that 


$$
\text { (A22) } \quad\left(\frac{p_{\mathrm{r}}}{\overline{\mathrm{P}}}\right)^{\alpha \sigma}=0.5 \mathrm{n} q \frac{\mathrm{E}\left[\mathrm{Hd}_{1,2}\right]^{\alpha(1-\gamma) /(1-\alpha \gamma)]}}{\left[\mathrm{Hd}_{1,2}\right]^{\alpha(1-\gamma) /(1-\alpha \gamma)}}
$$

Applying (A22) to (A19), infer (19c).

\section{Equation 22}

Equations (19a), (19c), (20), (21), and (A22) form a simultaneous equations system that allows us to solve for $\left[\frac{P_{C}}{\bar{P}}, n, I, L_{T}, l_{s}\right]$ as a function of structural variables (like $q, K$, and the productivity distribution). Equation (15) is the outcome of solving this system. 
Aizenman, Joshua. "Monetary and Real Shocks, Productive Capacity and Exchange Rate Regimes." 1993, forthcoming, Economica.

Azariadis, Costas. "Implicit Contracts and Unemployment Equilibria," Journal of Political Economy 83, December 1975, pp. 1183-1202.

Brainard, S. Lael. "An Empirical Assessment of the Factor Proportions Explanation of Multinational Sales," Working paper 4583, December 1993.

Dixit, Avinash K. and Stiglitz, Joseph. "Monopolistic Competition and Optimum Product Diversity," American Economic Review 67, 1977, pp. 297-308.

Edwards, Sebastian. "Capital Flows, Foreign Direct Investment, and Debt- Equity Swaps," NBER W.P. no. 3497, October 1989.

Ethier, Wilfred J. "Dumping", Iournal of Political Economy June 1982, pp. 487-506. . "The Multinational Firm," Ouarterly Journal of Economics, 1986, pp. 806-33.

Froot, Kenneth A. and Jeremy C. Stein, "Exchange Rates and Foreign Direct Investment," Working Paper no. 2914, March 1989.

Goldberg, Linda, "Exchange Rates and Investment in the United States Industry," manuscript, August 1991.

Helpman Elhanan. "A Simple Theory of International Trade with Multinational Corporations," Journal of Political Economy p. 451. and Paul Krugman, Market Structure and Foreign Trade, the MIT Press, 1985.

Klein, Michael and Eric Rosengren, "Foreign Direct Investment Outflow From The U. S.," manuscript, 1990.

Markusen, James. "Multinationals, Multi-plant Economics, and the Gains From Trade," Joumal of International Economics, 16, pp. 205.

Matusz, Steven J. "The Heckscher-Ohlin-Samuelson Model with Implicit Contracts," Ouarterly Iournal of Economics November 1985, pp. 1313-30. 
- 30 -

Lizando, Saul J. "Foreign Direct Investment," IMF Working paper 90/63, 1990.

Slaughter, Matthew J. "International Trade, Multinational Corporations, and American Wage Divergence in the 1980's," manuscript, MIT, 1993. 